\title{
Endometrial ablation for women with heavy menstrual bleeding: A systematic review and network meta-analysis
}

\author{
Chung Shen Chean ${ }^{1}$, Yuen Wei Liao ${ }^{1}$, Jessica Potts ${ }^{2}$, Steven Toh ${ }^{1}$, Syafira Shaman ${ }^{1}$, Shi \\ Sum Poon ${ }^{1}$, and Adel Soltan ${ }^{3}$ \\ ${ }^{1}$ University of Liverpool Faculty of Health and Life Sciences \\ ${ }^{2}$ Keele University School of Primary Community and Social Care \\ ${ }^{3}$ Liverpool Women's Hospital NHS Foundation Trust
}

October 19, 2021

\begin{abstract}
Background: Endometrial ablation (EA) is a less invasive treatment alternative to hysterectomy for heavy menstrual bleeding, but which ablation technique works best remains unknown. Objectives: A systematic review and network meta-analysis to evaluate the efficacy of different first and second generation EA techniques. Search strategy: A systematic search of online databases from inception. Selection criteria: Randomised controlled trials of EA techniques. Data Collection and Analysis: Primary outcomes (amenorrhoea rate and patient satisfaction rate at short (up to 12 months), intermediate (between 12 months and 5 years), and long term (5 years or more) follow-up) and secondary outcomes (re-intervention rate) were compared between first and second generation EA techniques. Treatment effects of different second generation EA techniques were compared. Main results: Comparing first versus second generation EA, there was no significant difference in amenorrhoea rates at short (OR 1.27, 95\%CI 0.83-1.95), intermediate (OR 0.79, 95\%CI 0.48-1.30), or long term (OR 1.39, 95\%CI 0.94-2.07) follow-up. This was the same with patient satisfaction rates at short (OR 0.76, 95\%CI 0.53-1.09), intermediate (OR 0.76, 95\%CI 0.471.23), and long term (OR 0.68, 95\% CI 0.31-1.51) follow-up. No difference in re-intervention rates was demonstrated. Highest amenorrhoea rate was achieved with bipolar radiofrequency, followed by hydrothermablation, microwave and thermal balloon ablation. Conclusions: Second generation EA seem to be as effective as first generation techniques in achieving amenorrhoea, high patient satisfaction and low re-intervention rate. Bipolar radiofrequency ablation seems to be the best amongst second generation EA in achieving amenorrhoea. Funding: None Keywords: 'endometrial ablation', 'menorrhagia', 'heavy menstrual bleeding'
\end{abstract}

\section{Hosted file}

Main document.docx available at https://authorea.com/users/441801/articles/542256endometrial-ablation-for-women-with-heavy-menstrual-bleeding-a-systematic-review-andnetwork-meta-analysis 
Figure 1: Amenorrhoea rate

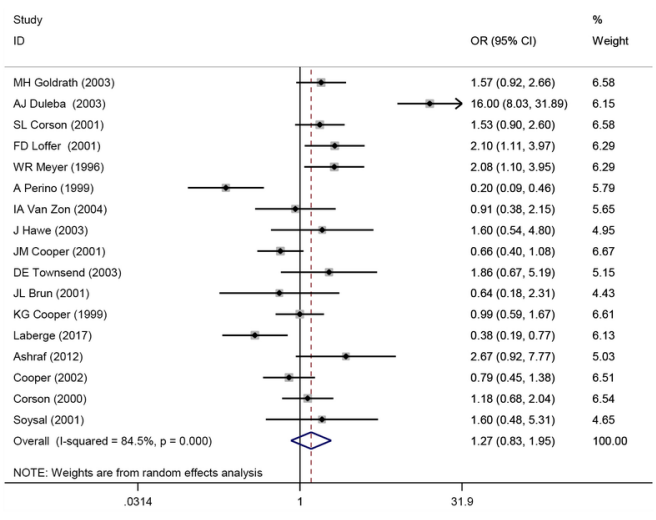

a: Short term follow-up

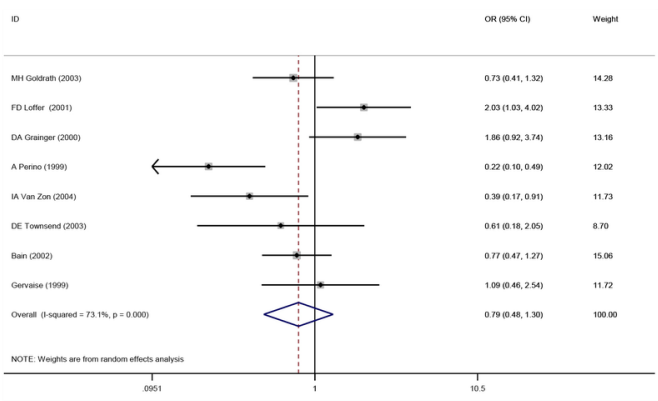

b: Intermediate follow-up

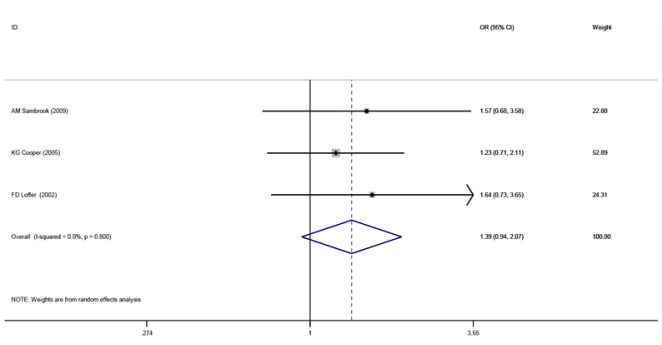

c: Long term follow-up 


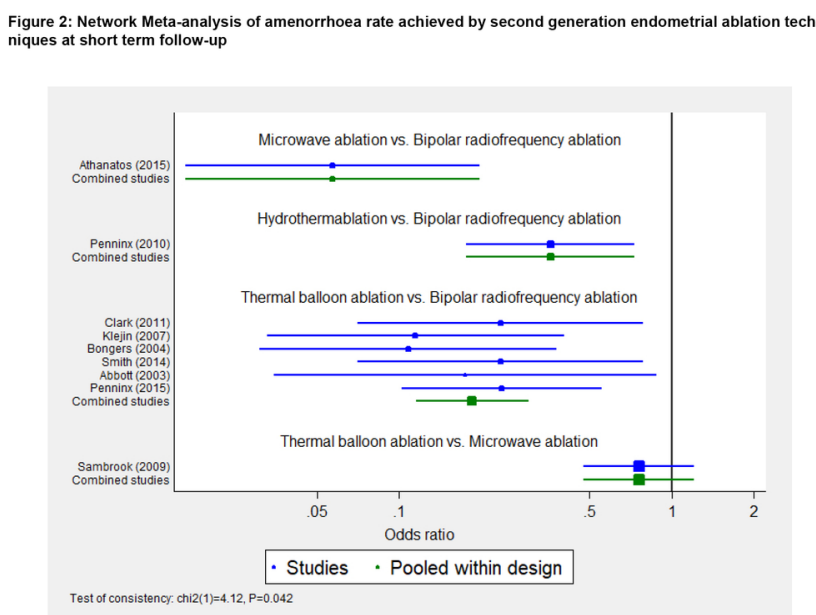

\section{Hosted file}

Table 1 - Pairwise comparisons.docx available at https://authorea.com/users/441801/articles/ 542256-endometrial-ablation-for-women-with-heavy-menstrual-bleeding-a-systematic-reviewand-network-meta-analysis

\section{Hosted file}

Table 2 - Pairwise and NMA results.docx available at https://authorea.com/users/441801/ articles/542256-endometrial-ablation-for-women-with-heavy-menstrual-bleeding-asystematic-review-and-network-meta-analysis 